\title{
Building Duration / El Portico de los Huespedes
}

\section{PATRICIA GUAITA}

Swiss Federal Institute of Technology (EPFL)

\section{RAFFAEL BAUR}

Swiss Federal Institute of Technology (EPFL)

\section{SONY DEVABHAKTUNI}

The University of Hong Kong

DAVID JOLLY
Pontificia Universidad Católica de Valparaíso

The fixed nature of the tasks, rudimentary tools and the short, three-week period generate an intensity. On-site discussions of tests made in different modes and at various scales guide decisions. These decisions are also informed by the traces of the past manifest by El Portico as it is encountered in every moment, and by the work students know will continue in the years to come, by other hands; it is with this knowledge that the project is able to transmit an understanding of architecture that links past to future, bringing into presence the uncertain and open-ended potential of the life of a work and its fragility as a human endeavor.
The project's development from this beginning has not been determined by a fixed set of drawings. Instead, each year, the work begins anew when students encounter El Portico and the traces of time, labor, craft and thought left by those before them. Students are given a task (a plaza, walls, an enclosure, columns, a floor) that leads the project towards some additional possibility of appropriation. Working on these tasks, they draw, model and build full-scale mock-ups to test possibilities. They work in spaces nearby or, in recent years, bring drawing tables and tools under the completed roof working with the wind and winter sun.

In the first year, students defined the site and erected a structural frame on wooden piles founded into the sand. The following summer, a brick plaza tied El Portico into the landscape; a secondary roof structure, also built the second year, was clad the third using inexpensive wooden siding disposed in four waterproof layers. The fourth year, three wall fragments began to suggest enclosure. This past year -- the fifth -- a possibility for habitation: an inside defined by a concave wall punctured with lean windows; a locking door, a finished floor of wood and concrete and a brick plaza just outside. In intervals between each August, other teams of students led by partners in Chile intervened: a field of concrete columns cast with fabric formwork; wooden ribs and a concrete slab that formed the shell of the wing completed this past year. 

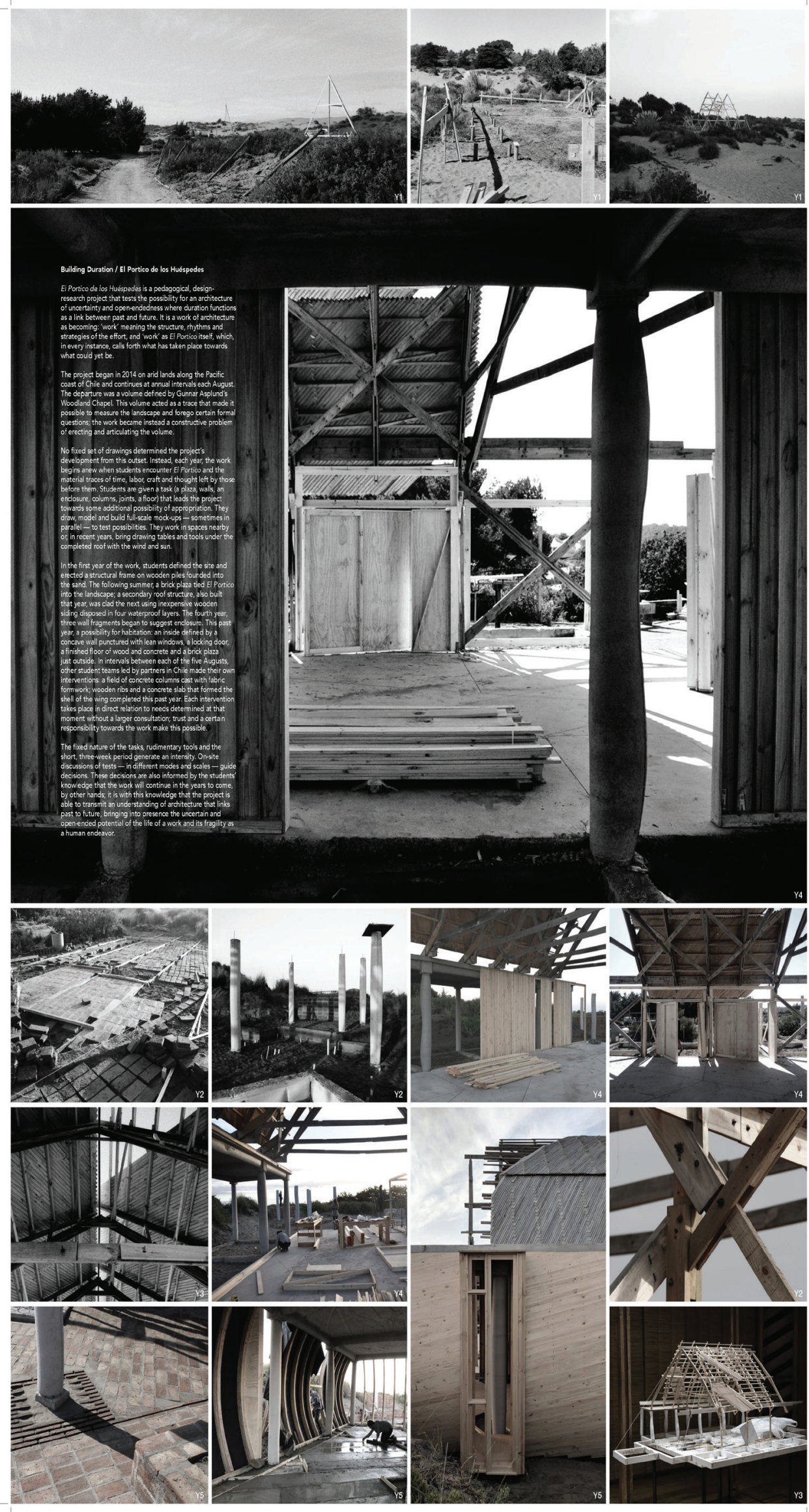